\title{
Relações de gênero e processos de despatriarcalização das famílias sob a ótica das crianças
}

\author{
Ana Paula Pereira Gomes Gibim ${ }^{1}$ \\ Daniela Finco ${ }^{2}$
}

\begin{abstract}
RESUMO: Este artigo apresenta uma pesquisa, realizada em uma instituição de Educação Infantil da rede municipal de São Paulo, que buscou investigar as concepções das crianças relacionadas à família. 0 trabalho reflete sobre as transformações na unidade doméstica decorrentes, principalmente, do empoderamento feminino que tem sido apontado como um dos propulsores da despratriarcalização familiar decorrente da falência do modelo tradicional conjugal que tem dado lugar a novas formas de configuração familiar. Problematiza também as violências e subordinação de gênero que marcam as relações na família e na sociedade, entre homens e mulheres, nas quais as crianças estão participando e vivenciando. A partir dos estudos de gênero e feministas, discute as formas estratégias de manutenção do sistema patriarcal em nossa sociedade, as formas colonizadoras de se conceber família, a partir de uma perspectiva patriarcal que desconsidera as novas configurações familiares. Tem como base o referencial teórico metodológico da Sociologia da Infância, que considera a criança como protagonista da pesquisa utilizando-se da etnografia com as crianças para revelar suas formas de reflexão. Busca contribuir trazendo reflexões acerca das relações que marcam as desigualdades sociais desde a pequena infância, propondo a desconstrução de postulados coloniais produtores de imagens distorcidas e cristalizadas das famílias.
\end{abstract}

Palavras-chave: Famílias. Relações de gênero. Sociologia da Infância

\section{Gender relations and family depatrialization processes from the perspective of children}

\begin{abstract}
This article presents a research carried out in an institution of Early Childhood Education of the municipal network of São Paulo, which sought to investigate the conceptions of children related to the family. The work reflects on the transformations in the domestic unit, mainly due to the female empowerment that has been pointed out as one of the propellers of the family depratriarchalization due to the bankruptcy of the traditional conjugal model that has given rise to new forms of family configuration. It also problematizes the gender-based violence and subordination that marks relationships in the family and in society, between men and women, in which children are participating and experiencing. From the studies of gender and feminists, it discusses the strategies of maintaining the patriarchal system in our society, the colonizing ways of conceiving the family, from a patriarchal perspective that ignores the new family configurations. It is based on the theoretical methodological reference of Sociology of Childhood, which considers the child as the protagonist of the research using ethnography with children to reveal their forms of reflection. It seeks to contribute by bringing reflections about the relations that mark the social inequalities from the small childhood, proposing the deconstruction of colonial postulates producing distorted and crystallized images of the families.
\end{abstract}

Keywords: Families. Gender relations. Sociology of Childhood

- Enviado em 29/11/2016

- Aprovado em 05/12/2016

\footnotetext{
${ }^{1}$ Mestranda pelo programa de pós-graduação em Educação da Universidade Federal de São Paulo e integrante do Grupo de Pesquisa sobre Gênero, Educação da Pequena Infância, Cultura e Sociedade - UNIFESP; anapaulapggibim@gmail.com

2 Professora Adjunta na Universidade Federal de São Paulo e líder do Grupo de Pesquisa sobre Gênero, Educação da Pequena Infância, Cultura e Sociedade - UNIFESP; danielafinco@gmail.com
} 


\section{INTRODUÇÃO}

Este artigo aborda a questão dos diferentes arranjos familiares, das marcas do feminino e do masculino a partir da perspectiva das crianças, apresenta reflexões acerca das famílias contemporâneas considerando as diferentes dinâmicas familiares a partir da ótica das crianças. Apresenta uma pesquisa, realizada em uma instituição de Educação Infantil da rede municipal de São Paulo, com uma turma de trinta e cinco crianças entre quatro e cinco anos de idade, que buscou investigar suas concepções relacionadas à família. 0 artigo reflete sobre as violências e subordinação de gênero que marcam as relações na família e na sociedade, entre homens e mulheres, nas quais as crianças estão participando e vivenciando. Busca a perspectiva das crianças, a partir do desenho e da oralidade, considerando as experiências narradas e interpretadas pelos meninos e meninas em seus desenhos. Ao "ler" e interpretar os desenhos das crianças pequenas é possível identificar os símbolos culturais presentes nos desenhos, nos traços, nas cores, nos assuntos representados e narrados pelas crianças. Com a multiplicidade de histórias registradas no papel, e interpretadas a partir de suas experiências culturais, as crianças compartilham mensagens que revelam diferentes representações de gênero. 0 artigo procura contribuir para a visibilidade da emergência de novas configurações familiares. Trata-se de uma reflexão que considera as novas demandas sociais, econômicas e culturais que têm transformado a sociedade, como apontam os estudos de Castells (1999) e Therborn (2006), nas quais as crianças participam ativamente.

Por muito tempo a infância e a criança foram cercadas por um discurso normatizador proveniente das ciências ligadas à saúde, como medicina e psicologia. Tais discursos, além de prever uma série normatizações que homogeneizavam as crianças, concebia a visão adultocêntrica como verdade absoluta. Daí a concepção de criança como imatura, inacabada e natural que somente alcançaria a maturidade e completude ao deixar de ser natural e ser inserida no campo social, por tanto, deixando de ser criança.

Contudo, a Sociologia da Infância veio para desconstruir esta visão centrada na imaturidade biológica para propor uma visão de criança enquanto sujeito produtor de cultura e protagonista de suas experiências, como "atores sociais e sujeitos de direitos, construtoras da história e cultura" (Faria e Finco, 2011, p.12). Assim como a Sociologia da Infância aponta para uma nova forma de se conceber a infância e a criança, estudos sociológicos 
contemporâneos sobre famílias (Sarti, 2007; 2004; Fonseca, 2005; 2002) apontam para a necessidade de considerar a emergência de novas dinâmicas familiares em detrimento a um modelo patriarcal de família nuclear.

Neste sentido, atrelado aos estudos pós-colonialistas, a proposta deste trabalho é pensar na condição daquelas que, por muito tempo, foram consideradas subalternas, excluídas, sujeitadas e desumanizadas pelo fato de não serem ouvidas e enxergadas, de não serem compreendidas e serem vistas a partir de um único ponto de vista que é aquele do adulto homem, a saber, crianças e mulheres.

A pesquisa visa construir um olhar feminista para os direitos das crianças (Finco, Faria e Gobbi, 2015), trazendo sobretudo a creche como este lócus histórico de luta feminista, visando outras práticas pedagógicas, conscientizando as professoras e professores, envolvendo as famílias, buscando transformar a realidade educativa de milhares de crianças, bem como fomentar novas questões de pesquisas, em busca de práxis emancipatória descolonizadoras. Descolonizar as lentes sob uma nova ótica de gênero nos permite enxergar as origens das violências, como a força do patriarcado, marcado pela desvalorização do feminino, pela divisão sexual do trabalho e os reflexos deste sistema nas instituições de educação infantil, e também ressaltam o desafio que essas teorias colocam para análises culturais (Bacchetta e Fantane, 2015). Além disso destaca a participação das crianças no processo da pesquisa. Dar visibilidade e ouvir o que elas têm a dizer é essencial para a compreensão do conceito de família, tendo que em vista que as crianças não são passivas nos processos sociais, mas se apropriam e reelaboram a cultura na qual estão imersas.

\section{FAMÍLIA PARA ALÉM DE UM MODELO HEGEMÔNICAO PATRIARCAL}

Buscamos apresentar uma reflexão sobre uma Pedagogia da Infância, e uma Pedagogia da Emancipação e das Diferenças, que se encontram no campo dialético, e que tem possibilidades de mediação para se pensar em uma educação para a emancipação humana, para além das armadilhas do binarismo de gênero. As reflexões nos ajudam a confrontar as fronteiras do feminino e masculino, tecendo reflexões para além do binarismo e da estabilidade patriarcal; (re)construindo a valorização do feminino, a revisão das dicotomias de gênero, e problematizando o feminino e o masculino enquanto ideias em constante 
movimento e disputa. Permite compreender e problematizar a autoridade institucionalmente imposta do homem sobre a mulher, do adulto sobre a criança, posta pelo sistema patriarcal. Compreender também a relação de poder que destitui a mulher de direitos sociais e caracteriza a criança como ser incapaz e que está disseminada em toda a sociedade, contaminando relações pessoais, familiares e estruturas sociais ainda nos dias de hoje.

Assim, para compreender as famílias na contemporaneidade é necessário desfazer a confusão existente entre família e unidade doméstica (Sarti, 2007). As alterações na unidade doméstica, casa, em decorrência das dificuldades enfrentadas por seus membros em desempenhar os seus "papéis" desencadeiam-se em arranjos que envolvem a rede de parentesco a fim de viabilizar a existência da família. A compreensão das famílias entendidas enquanto unidades domésticas desconsidera a rede de relações que se estabelecem entre os seus membros (ibidem, p. 29).

Por muito tempo a ideia de família esteve atrelada à sua constituição nuclear tradicional com pai, mãe e filho(a). Trata-se de um conceito heteronormativo e patriarcal, que concebe um único modelo familiar como ideal. Por meio de símbolos culturalmente disponíveis que evocam representações múltiplas; conceitos normativos expressos em doutrinas científicas, educativas, políticas ou jurídicas; noções políticas referentes às organizações e instituições sociais que determinam aos sujeitos formas de se relacionarem e de se organizarem socialmente; e processos de formação da identidade subjetiva dos sujeitos que expressam formas distintas de controle e poder sobre estes (Scott, 1995) é que tal instituição foi sendo mantida e consolidada.

No caso brasileiro, discutir família envolve uma discussão geracional e de gênero para a compreensão dos relacionamentos entre adultos e crianças, uma vez que tais relações familiares são marcadas por valores patriarcais que regem nossa sociedade, por meio da autoridade do masculino sobre o feminino, do adulto sobre a criança, sendo esta uma forma legitimada organizacional de manutenção dos valores patriarcais (Castells, 1999).

Contudo, dados censitários (2010) revelam o declínio do modelo patriarcal como hegemônico na sociedade brasileira. "A transformação na economia e do mercado de trabalho associada à abertura de oportunidades para as mulheres no campo da educação", "transformações tecnológicas ocorridas na biologia, farmacologia e medicina", "desenvolvimento do movimento feminista" e "rápida difusão de ideias em uma cultura 
globalizada" corroboraram para o declínio das formas tradicionais de família com "papéis" preestabelecidos (Castells, 1999).

A última pesquisa de recenseamento social brasileiro3, 2010, aponta para mudanças substanciais nas configurações familiares em decorrência de aspectos relacionados às categorias gênero e geração. De acordo com o estudo (IBGE, 2010), cerca de 37,3\% das famílias brasileiras são chefiadas por mulheres, número crescente se comparado ao ano de 2000 que era de 22,2\%. A taxa de casais sem filhos aumentou 5,3\%, enquanto o número de casados caiu 2,2\% e aumentou o número de divorciados, de 1,7\% para 3,1\%. As uniões informais (consensuais) aumentaram 7,8\% em 10 anos, enquanto que as uniões formalizadas caiu 6,5\%. Mas o que todos estes números apontam? O que eles querem dizer?

Segundo uma entrevista publicada pelo Instituto Humanistas Unisinos ${ }^{4}$ (2012) com pesquisadores da Escola Nacional de Ciências Estatísticas do IBGE, gênero e geração são fundamentais para a compreensão da complexidade das famílias brasileiras contemporâneas. De acordo com os estudiosos, o aumento da esperança de vida e a queda na taxa de fecundidade produziu um novo perfil populacional com elevado índice de idosos. Além disso, com o empoderamento feminino há um processo de "despatriarcalização da sociedade". Ambas mudanças refletem diretamente nas composições e estruturas familiares. Tais transformações não só abrem espaços para novos arranjos, mas também "diminui o peso social das famílias tradicionais".

Elza Berquó (1998), ao propor um balanço sobre os arranjos familiares no Brasil e suas mudanças na última década a partir de uma análise demográfica, afirma que a variabilidade a respeito do estado conjugal da população está diretamente ligada às novas configurações familiares. Para a autora (p. 412), "as uniões matrimoniais foram [e são] regidas por sistemas legais que variam ao longo do tempo", o que indica transformações e mudança de concepção sobre o que é ser família no Brasil. Isso, porque tanto as oportunidades quanto as fatalidades enfrentadas ao longo da vida moldam as biografias, e as situações nas quais ocorrem refletemse nas configurações familiares no Brasil.

Os processos relacionados às configurações familiares estão, portanto, imbricados em situações, tais como: fecundidade, mortalidade, divórcio e separação, recasamentos, para citar

\footnotetext{
3 “O Censo 2010 compreendeu um levantamento minucioso de todos os domicílios do país. Nos meses de coleta de dados e supervisão, 191 mil recenseadores visitaram 67,6 milhões de domicílios nos 5.565 municípios brasileiros para colher informações sobre quem somos, quanto somos, onde estamos e como vivemos" (IBGE).

${ }^{4}$ Entrevista disponível através do link: http://www.ihu.unisinos.br/entrevistas/515013-censo-2010-uma-famlia-pluralcomplexa-e-diversa.
} 
somente alguns que, por sua vez, são reflexos de processos mais amplos relacionados às transformações econômicas, sociais e culturais num dado momento histórico (Berquó, 1998). Neste sentido, mudança e permanência marcam a estrutura familiar brasileira do ponto de vista demográfico. Porém, a autora sugere que as maiores mudanças ocorrem no interior das famílias "assinaladas pela alteração da posição relativa da mulher e pelos novos padrões de relacionamento entre os membros da família" (ibidem, p. 415).

Acompanhamos no Brasil, então, um processo de transformação das relações intrafamiliares que estão cada vez mais perdendo seu caráter hierárquicos para dar lugar a relações mais igualitárias (Berquó, 1998). Isso é possível de observar, por exemplo, ao analisar a Tabela 1 que traz, em números percentuais, algumas pistas para refletir sobre estas mudanças de relacionamento, bem como algumas permanências sociais no que diz respeito aos arranjos domésticos.

Tabela 1: Distribuição de famílias por arranjos domésticos - Brasil 1970-2010

\begin{tabular}{l|lllll}
\multicolumn{1}{c}{ Arranjos Domésticos } & 1970 & 1980 & 1991 & 2000 & 2010 \\
\hline Casal com Filhos & 57,6 & 54,8 & 53,3 & 56,4 & 49,4 \\
Casal com filhos + Parentes + Agregados & 9,8 & 8,1 & 7,7 & 7,2 & 5,5 \\
Casal sem filhos & 9,2 & 10,6 & 11,0 & 13,0 & 17,7 \\
Casal sem filhos + Parentes + Agregados & 2,2 & 1,8 & 1,8 & 1,9 & 2,5 \\
Monoparental & 7,8 & 10,7 & 12,5 & 13,1 & 14,0 \\
Monoparental + Parentes + Agregados & 2,5 & 2,7 & 3,1 & 4,1 & 4,6 \\
Fonte: Fundação IBGE, censos 1970, 1980, 1991, 2000 e 2010. & & &
\end{tabular}

Embora a tradicional família nuclear ainda seja a sua maioria no contexto brasileiro, é possível observar a tendência declinante deste tipo de arranjo familiar acompanhado do aumento significativo de famílias sem filhos e de arranjos monoparentais. Isso reflete, a princípio, o maior empoderamento feminino já mencionado por Therborn (2006) e Castells(1999) relacionados ao domínio sobre seus corpos no que diz respeito à maternidade e a desierarquização das relações conjugais que tem possibilitados às mulheres poder de decisão sobre suas vidas matrimoniais. 
Tabela 2:Índice de monoparentalidade por sexo

\begin{tabular}{l|ll}
\multicolumn{1}{c}{ Tipo de Monoparentalidade } & 2000 & 2010 \\
\hline Mulheres com filhos + Parentes & 3,7 & 4,0 \\
Mulheres com filhos & 11,6 & 12,2 \\
Homens com filhos + Parentes & 0,4 & 0,6 \\
Homens com filhos & 1,5 & 1,8 \\
Total & 17,2 & 18,6
\end{tabular}

Fonte: Fundação IBGE, censos 2000 e 2010.

Há, portanto, uma complexificação das relações familiares que, decorrente de abalos externos e internos, desvinculam o caráter natural da família para transformá-la em um processo simbólico através do qual seus membros constroem relações fundamentadas por elos morais. Neste sentido, formam-se arranjos familiares fundamentados por laços simbólicos, e não apenas biológicos, que descontroem a concepção de família enquanto um conceito generalizador relacionado aos aspectos biológico reprodutivos.

A Família deve ser entendida a partir de sua dinâmica própria (Fonseca, 2002), através da qual seus membros assumem um compromisso moral diante do outro viabilizando a existência desta, por meio de uma rede de parentescos. Não é possível, portanto, operar com conceitos generalizadores tendo em vista que há formas distintas de ser família decorrentes de dinâmicas próprias ligadas à características temporais (geracionais) e espaciais (para além da unidade doméstica).

Entretanto, ainda que na sociedade brasileira não haja correspondência empírica imediata das famílias com um modelo patriarcal, tal modelo existe enquanto autoridade moral no imaginário social fundamentando uma concepção de família (Sarti, 1992). Este modelo é legitimado e consolidado a partir de formas de controle social por meio de símbolos culturais, conceitos normativos e processos de formação identitária que produzem relações desiguais entre homens e mulheres, meninos e meninas, operando enquanto conceito normatizador e hegemônico de família. Assim, o patriarcado enquanto modelo ideológico persiste enquanto representação e norma em uma sociedade cujas bases sociais, econômicas e políticas se construíram a partir de relações desiguais de exploração por meio da escravidão, do latifúndio e o patriarcado rural (Freyre, 2003). 


\section{CONTRIBUIÇÕES DOS ESTUDOS SOBRE A SOCIOLOGIA DA INFÂNCIA}

São inegáveis as contribuições dos estudos sobre as infâncias para a compreensão do modo como as crianças estão construindo suas representações. Florestan Fernandes foi um dos percursores sobre os estudos sociológicos sobre a infância no Brasil. Em sua clássica obra, O folclore e a mudança social na cidade de São Paulo, uma pesquisa datada da década de 1940, o autor apresenta um estudo sobre as culturas infantis a partir do folclore paulistano e traz alguns conceitos que são centrais nas discussões sobre as crianças e as infâncias. Podemos, com isso, reiterar a atualidade dos conceitos expressos em sua obra que, mesmo tendo sido resultado de um tempo histórico, social e cultural diferente do nosso atual cenário brasileiro, suas contribuições trazem conceitos contemporâneos que perpassam o campo da Sociologia da Infância. Neste sentido, sua sensibilidade e riqueza no olhar sobre o fenômeno que estudara nos possibilita articular suas discussões a de autores contemporâneos como Manoel J. Sarmento e Willian Corsaro, referências no campo dos estudos sobre a infância e a criança.

Mesmo vindo de uma tradição sociológica durkheimiana, Fernandes (1979) ousou e rompeu com alguns postulados ao constatar, em seu estudo sobre as trocinhas do bom retiro, que as crianças produzem cultura e que esta é constituída por elementos quase que exclusivos das crianças e caracterizada por sua natureza lúdica. A ludicidade percebida pelo autor faz parte dos quatro eixos estruturadores das culturas da infância (Sarmento, 2004) juntamente com a reiteração, a fantasia do real e a interatividade. Esta última, também foi enfatizada por Fernandes ao salientar a importância e o papel dos grupos infantis como suporte social para a produção cultural das crianças através do qual “adquirem, em interação, os diversos elementos do folclore infantil" (p. 215).

Já ao tratar sobre a produção cultural das crianças, Fernandes ressalta o processo interpretativo e não meramente reprodutivo desta cultura, semelhantemente ao conceito contemporâneo de reprodução interpretativa de Corsaro (2011). De acordo com o autor, "o mecanismo, pois, é simples: são elementos da cultura adulta, incorporados à cultura infantil por um processo de aceitação e nela mantidos com o correr do tempo" (Fernandes, 1979, p. 215):

Mas há outros elementos na cultura do grupo infantil. Nem tudo corresponde a coisas relativas ou provenientes da cultura dos adultos. Os próprios imaturos também elaboram, é óbvio, parte dos elementos de seu patrimônio cultural. Alguns desses 
elementos foram, mesmo, estruturados sobre moldes fornecidos pela vida interativa da "gente grande" (Fernandes, 1979, p. 216).

Ou seja, há quase 80 anos atrás Florestan Fernandes já havia percebido o papel ativo da criança na sociedade através dos grupos infantis por meio dos quais elas, até então consideradas como seres receptoras de cultura, produziam sua própria cultura. Não se trata de uma produção independente da cultura adulta, mas proveniente desta que é reelaborada pelas crianças; e também não é uma simples cópia, mas o "produto de um processo mais ou menos longo, de socialização desses imaturos, em situações de convivência regulada por sua própria vida social" (Fernandes, 1979, p. 217).

Estudos brasileiros contemporâneos (Faria e Finco, 2011) sobre a infância ampliam esta discussão ao problematizar formas sociais de colonização proveniente de uma cultura adultocêntrica e europeizada, propondo uma reflexão não homogeneizadora acerca do ser criança e viver as infâncias no Brasil.

\section{O QUE AS CRIANÇAS ESTÃO CONSTRUINDO SOBRE FAMÍLIA DIANTE DESSE CONTEXTO?}

Um constante desafio é a construção de procedimentos de pesquisa com crianças para o estudo das culturas produzidas pelas crianças, considerando a diversidade cultural brasileira. Os procedimentos investigativos com as crianças foram embasados nos estudos do campo da Sociologia da Infância que concebem a criança como ser inteligível, capaz de agir sobre a cultura e produzir uma nova, com base em suas formas especificamente infantis de agir, interpretar e ser no mundo (Faria e Finco, 2011). Compreende-se que a realidade social da criança é, então, construída a partir dos valores, condutas e expectativas vindas da cultura adulta e de suas ressignificações protagonizadas pelas próprias crianças, afinal as crianças criam e participam de suas próprias e exclusivas culturas de pares quando selecionam ou se apropriam criativamente de informações do mundo adulto para lidar com suas próprias e exclusivas preocupações (Corsaro, 2011). Refuta-se, então, a concepção de criança enquanto ser passivo, ahistórico e universal. As crianças, marcadas pelas estruturas e relações sociais que vivenciam, são co-construtoras da infância e da sociedade. Esta mudança de paradigma, 
colocada pela Sociologia da Infância, implica no movimento de "reposicionar as crianças como sujeitos, ao invés de objetos da investigação" (Christensen e James, 2005).

Assim, é possível pensar no que as crianças trazem sobre as suas famílias como sendo este um exercício descolonizador da visão de infância e criança, bem como da visão de família, uma vez que as crianças estão vivenciando experiências distintas à concepção hegemônica de família e a partir disso constroem representações distintas sobre o que é e como é ser família.

Durante um período de imersão de 8 meses na instituição de Educação Infantil foi possível realizar uma pesquisa etnográfica com as crianças, captando àquilo que elas trazem sobre família descolonizando o olhar centrado no/do adulto para dar margem a uma ciência centrada na criança, no seu modo de ver e viver o mundo a partir do seu ponto de vista, desconstruindo conceitos rígidos e homogeneizadores para compreender a multiplicidade de modos de ser e agir através dos quais as crianças vivenciam e significam as suas experiências e relações por meio da imaginação, do faz de conta e da ludicidade (Sarmento, 2004). Assim, como técnica de coleta de dados foram utilizadas observações participante, conversas, leitura de literatura infantil sobre família e coleta de desenhos junto às crianças.

As análises apontam como as crianças estão construindo as suas concepções a partir das interações com o mundo que as cercam: família, mídia, literatura, igreja, entre outros. Tais concepções estão atreladas às construções sociais de um ideal de família calcado sob bases patriarcais. Entretanto, seria muito equívoco pensar a criança como passiva neste processo, se apropriando de tudo quanto lhes propiciam de experiências sem significa-las. Por meio de sua identidade cultural própria (Sarmento, 2004) as crianças se apropriam da cultura disponível reelaborando-a e dando um sentido particular por meio do qual elas irão simbolizar, representar e entender esta cultura (Corsaro, 2011). Desta forma, não há somente permanências no que diz respeito à construção das relações de gênero, mas há transgressões às normas e a construção de relações igualitárias por meio da reflexão propiciada nos momentos de trocas, sejam elas através dos relacionamentos intergeracionais ou intrageracionais.

A pesquisa procura chamar a atenção ao fato de que "as crianças são eminentemente parte da sociedade e do mundo" (Qvortrup, 2011) e vivenciam os acontecimentos de nossa sociedade de acordo com suas especificidades, assim como os adultos, jovens e idosas, vivenciando violências de gênero. Como são parte da sociedade, todos os eventos, grandes e pequenos, terão procedimentos relacionados às crianças, e, em consequência, elas terão 
reinvidicações a serem consideradas nas análises e debates acerca de qualquer questão social maior. Ao questionar o que estas mudanças significam para as crianças, para suas vidas cotidianas, é importante lembrar que o desenvolvimento econômico, político e social mudou a estrutura da família, a economia da infância na interface com a família e sociedade, a justiça distributiva em termos de equidade geral, e mesmo os direitos das crianças, os quais finalmente foram vistos no processo de cidadania das crianças.

As crianças trazem em suas falas construções que testificam a sua atuação social através de um processo ativo e reflexivo das experiências, por meio das quais elas se apropriam e reelaboram a cultura dos adultos. No caso da concepção de família, apesar de haver indícios de que as crianças trazem em suas falas uma concepção patriarcal, as formas de significação desta concepção trazem outras marcas que apontam para um despatriarcalização das relações familiares e do próprio conceito de família.

Ao serem solicitadas para desenharem suas famílias, as crianças trazem que família não é necessariamente aqueles que moram numa mesma unidade doméstica que a delas. A presença na família de membros que não coabitam com as crianças se dá pela complexificação das relações familiares que, diante das condições sociais, exigem a negociação das responsabilidades criando um elo moral entre seus membros (Sarti, 2004).

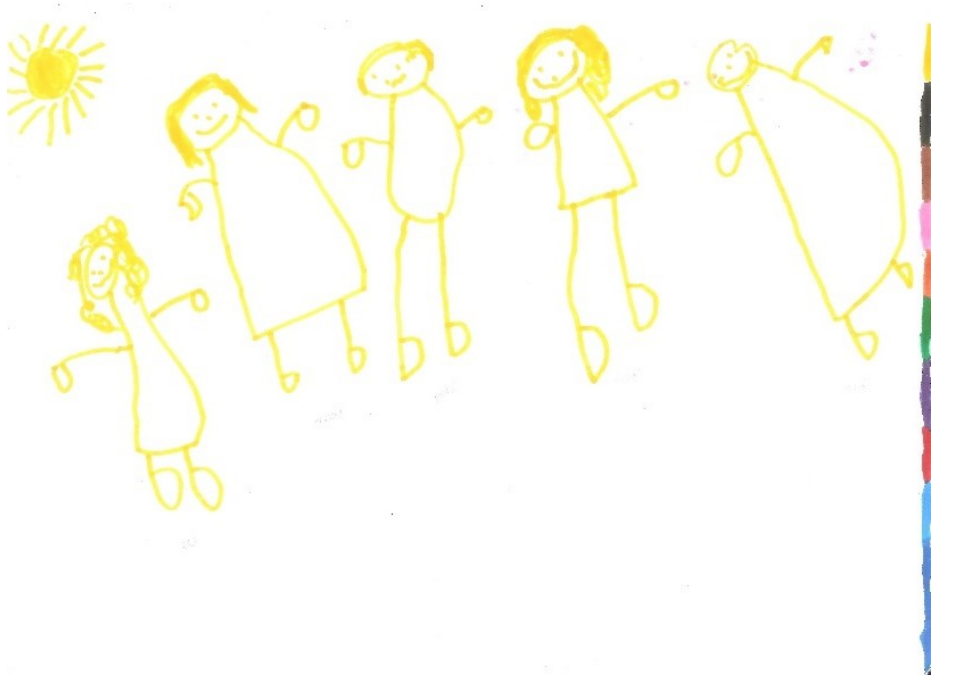

Geovanna - 5 anos: “Eu, minha mãe, minha vó, meu vô e minha irmã” 


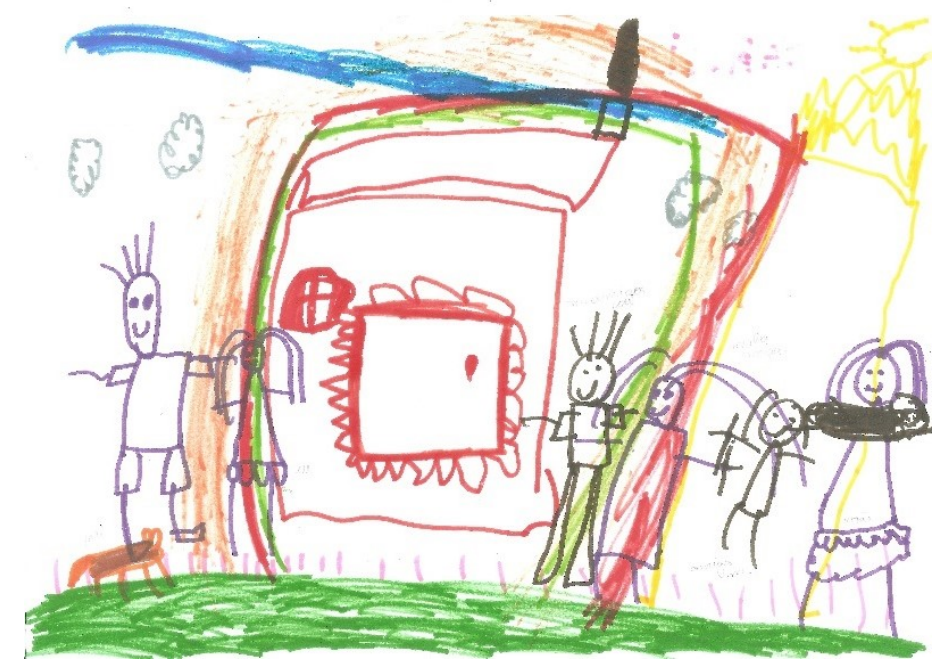

Carolina - 5 anos: "Eu fiz meu pai, eu, meu vô, minha vó, a miga da minha vó e minha mãe segurando a bebê".

Geovanna e Carolina, por exemplo, não moram com suas avós, mas as trazem em seus desenhos de família, assim como suas mães também as trouxeram quando solicitadas a desenhar a família. Tanto Geovanna como Carolina convivem diariamente com suas avós nos momentos em que as mães não podem estar com elas, seja em decorrência do trabalho, seja em decorrência dos estudos. As relações familiares vão além dos consanguíneos, apoiando-se em outros membros cujo laço moral determinará as obrigações diante das responsabilidades negociadas. Sobre este assunto, é particularmente interessante a análise de autores que apontam para a redefinição dos "papéis" sociais com base na construção de relações fundamentadas pelo compromisso moral diante da família dada as necessidades intrinsecamente ligadas às condições sociais (Sarti, 2004), o que deslegitima a família patriarcal enquanto única e verdadeira forma familiar. 


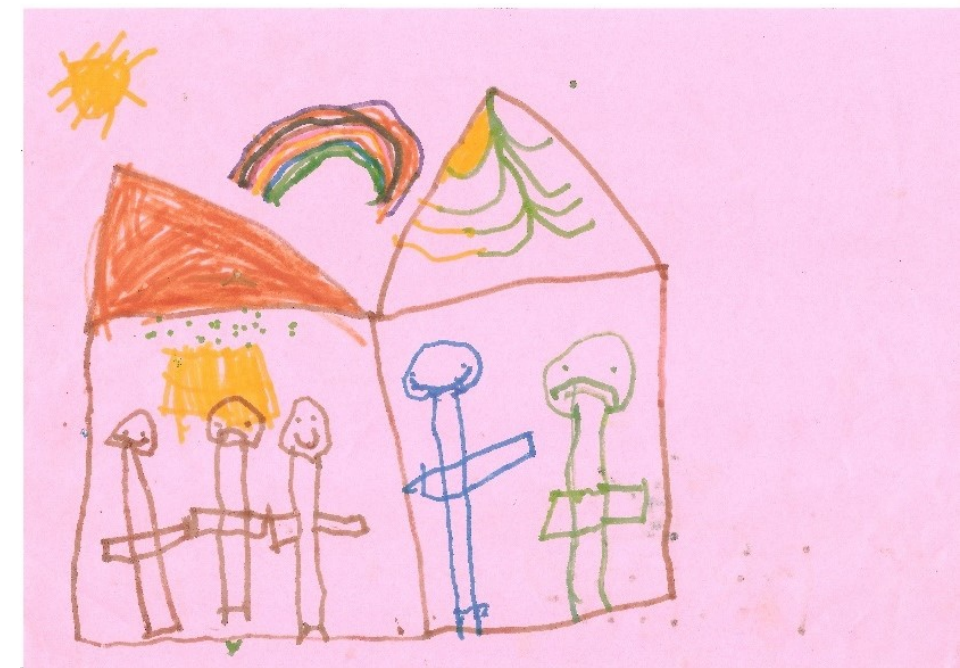

Bruno - 5 anos: "Eu desenhei minha mãe, meu pai, eu, minha vó e meu vô"

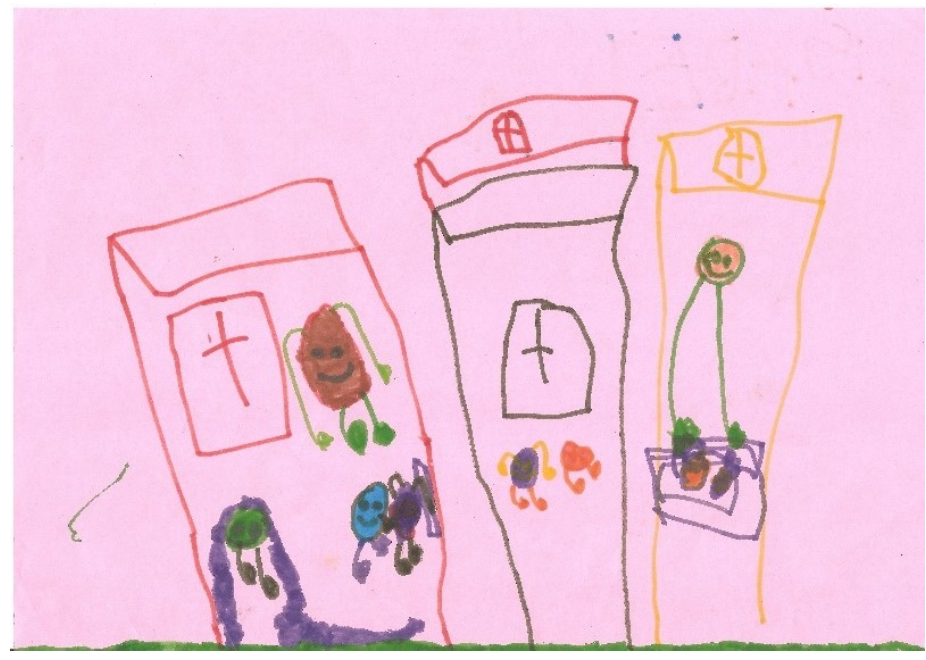

Isabela - 5 anos: "Aqui eu to fazendo eu na casa da minha vó, meu tio tá na casa da minha vó".

Outro exemplo são os desenhos feitos por Bruno, que mora com sua mãe e seus avós, e por Isabela, que mora com sua mãe e seu pai. Foi solicitado às crianças que desenhassem a casa e as pessoas que moram junto com elas. A confusão entre unidade doméstica e família é algo recorrente, contudo, é interessante perceber que o desenho de Bruno e de Isabela aponta justamente para esta diferenciação, evidenciando uma concepção de família que ultrapassa as barreiras da unidade doméstica, acoplando outros membros, formando em uma rede de parentescos (Fonseca, 2005). Nesta rede percebemos tanto a característica temporal, com a presença dos avós, como espacial, envolvendo outras unidades domésticas. 
Durante as brincadeiras na brinquedoteca, espaço organizado para a brincadeira de faz-de-conta, e com as caixas temáticas na sala da turma de crianças, é possível perceber também como as crianças trazem a reelaboração dos valores familiares, incluindo/excluindo personagens às famílias e funções compartilhadas entre seus membros. É possível observar as meninas constituírem grandes comunidades de mulheres com "bebês" através das quais o cuidado e educação são compartilhados com outras mulheres intituladas "amigas", "filhas" e "mães", enquanto as primeiras saem para trabalhar ou ir ao "salão de beleza". Assim como também é possível observar os meninos despenhando tarefas domésticas como lavar, limpar e fazer comida nas brincadeiras de "casinha" sem incluir ou necessitar da figura feminina.

0 relato a seguir, extraído do caderno de campo, reflete o compartilhamento de práticas de cuidados e educação para além dos laços biológico, algo muito recorrente nas brincadeiras na brinquedoteca entre as meninas, refletindo não somente o caráter de comunidade e auxílio mútuo entre elas, mas também a circulação de crianças que é algo muito presente no cotidiano das famílias estudadas:

\section{Relato 11:}

Ao irmos para a brinquedoteca algumas meninas do grupo me convidaram para participar da brincadeira que seria um chá de bebê. Primeiro eu deveria me aprontar na penteadeira - outras meninas estavam me aguardando por lá - e depois deveria ir [pra festa] quando estivesse tudo pronto. Fui até a penteadeira e me sentei. Enquanto uma arrumava meu cabelo a outra ajudava, uma terceira estava com um bebê e pediu para que eu cuidasse dele enquanto ela me maquiava. Escolhi uma roupa do cabideiro e coloquei. Observei, enquanto me arrumava, que as meninas organizaram todas as cadeiras do espaço (...) em fileira. (...) Enquanto uma varria, a outra arrumava a cozinha, espaço onde seria a festa (...). Chegando lá, percebi que todas as convidadas estavam com seus bebês (...). Algumas das meninas me mostravam suas bebês: "quer segurar a minha bebê?”, "cuida da minha filha que eu já volto”.

\section{CONSIDERAÇÕES FINAIS}

As crianças trazem suas concepções que são refletidas e reelaboradas através das brincadeiras, do faz de conta e dos desenhos. É possível observar que mesmo em meio às noções cristalizadas instituídas culturalmente e que evocam uma representação de família patriarcal nuclear, as crianças estão refletindo sobre as suas experiências e trazendo a 
desconstrução destes postulados, apontando para diversos arranjos de famílias e formas descolonizadoras de conceber a família.

Nos desenhos e falas das crianças podemos perceber que as famílias são significadas tendo em vista uma rede de parentesco ligada por laços morais (Sarti, 2004; 2007) cujo sistema apresenta características temporais e espaciais (Fonseca, 2005) próprias. Apontam também que as famílias não se delimitam à unidade doméstica (Sarti, 2004; 2007; Fonseca, 2002; 2005) e que há compartilhamento de práticas de cuidado e educação entre outros para além dos consanguíneos (Fonseca, 2006; Sarti, 2004) nos trazendo elementos para descolonizar nosso olhar.

À medida em que assumimos um posicionamento descolonizador da família e da infância, pretendemos contribuir para uma reflexão que dê visibilidade aos grupos marginalizados, como mulheres, negros, gays, crianças, imigrantes, velhos, entre tantos outros que são ignorados nas ciências em suas particularidades e sujeitados à visões cientificista estereotipadas. Pretende-se, com esta pesquisa, olhar de forma mais atenta e reflexiva para as estratégias de violência e subordinação que marcam as relações e concepções sobre as famílias as quais as crianças trazem.

A visão pós-colonialista além de propor e contribuir para reflexão acerca das relações que marcam as desigualdades e marginalização dos grupos sociais, propõem também a desconstrução de postulados coloniais produtores de imagens distorcidas e cristalizadas de sujeitos, povos e nações, denunciando que tais relações são criadas em contextos sociais, políticos, econômicos e culturais específicos (Faria et al, 2015). Diante disso, é preciso refletir e olhar minuciosamente para as relações construídas nas famílias e destas com a sociedade de modo a descolonizar e desconstruir a concepção de família hegemônica e patriarcal gestada no século XVI no Brasil, e dar visibilidade para atores comumente deixados à margem em uma sociedade machista, capitalista e adultocêntrica como a nossa sociedade.

\section{REFERÊNCIAS}

BACCHETTA, Paola; FANTANE, Laura. Femminismo queer postcoloniali: critiche transnazionali all'omofobia, all'islamofobia e all'omonazionalismo. Ombre corte/Culture: Verona, Italia, 2015. 
BERQUÓ, Elza. "Arranjos familiares no Brasil: Uma visão demográfica". In: SCHWARCS, Lilia Moritz (Org.). História da vida privada no Brasil: contrastes da intimidade contemporânea, vol. 4, São Paulo: Companhia das letras, 1998, p. 411-437.

CASTELLS, Manuel. 0 fim do patriarcalismo: movimentos sociais, família e sexualidade na era da informação. In: A era da informação: economia, sociedade e cultura, vol.2 - 0 poder da identidade. São Paulo: Paz e Terra, 1999.

CORSARO, William A. Sociologia da infância. Porto Alegre: Artmed, 2011.

CHRISTENSEN, Pia; JAMES, Allison (org.). Investigação com crianças: Perspectivas e práticas. Porto, Portugal: Escola Superior de Educação de Paula Frasinetti, 2005.

FARIA, Ana Lúcia G. de e FINCO, Daniela. (Orgs.). Sociologia da Infância no Brasil. Campinas: Autores Associados, 2011.

FARIA, Ana Lúcia G. de, et al (Orgs). Infâncias e pós colonialismo: pesquisas em busca de Pedagogias descolonizadoras. Campinas: Leitura Crítica, 2015.

FERNANDES, Florestan. Folclore e mudança social na cidade de São Paulo. 2ª ed., Petrópolis: Vozes, 1979.

FINCO, Daniela; FARIA, Ana Lucia Goulart de. GOBBI, Marcia. Creche e Feminismo: desafios atuais para uma educação descolonizadora. Campinas, SP: Edições Leitura Crítica; Associação de Leitura do Brasil - ALB; São Paulo: Fundação Carlos Chagas - FCC, 2015.

FONSECA, Cláudia. Olhares antropológicos sobre a família contemporânea. Participação na Mesa Redonda "O lugar da família na ciência contemporânea: desafios e tendências na pesquisa”. Congresso Internacional Pesquisando a Família, Florianópolis 24-26 de abril, 2002.

"Concepções de família e práticas de intervenção: uma contribuição antropológica". Saúde e Sociedade. v.14, n.2, maio-ago 2005, p.50-59.

"Da circulação de crianças à adoção internacional: questões de pertencimento e posse". In: Cadernos Pagu (26), janeiro-junho de 2006: p.11-43.

FREYRE, Gilberto. Casa-grande \& senzala: formação da família brasileira sob o regime da economia patriarcal. 48ª ed., São Paulo: Global, 2003.

SARMENTO, Manuel Jacinto. "As culturas da infância nas encruzilhadas da $2^{2}$ modernidade". In: SARMENTO, M.J.; CERISARA, A.B. (Orgs.). Crianças e miúdos: perspectivas sóciopedagógicas da infância e educação. Porto: Asa, 2004. P. 9-34.

SARTI, Cynthia Andersen. "Família patriarcal entre os pobres urbanos?". In: Caderno de Pesquisa, São Paulo, n.82, p. 37-41, ago. 1992, p. 37-41

2004, p. 11-28. “A família como ordem simbólica”. In: Psicologia USP, São Paulo, v. 15, n. 3,

Cortez, 2007.

. A família como espelho: um estudo sobre a moral dos pobres. São Paulo:

SCOTT, Joan Wallach. "Gênero: uma categoria útil de análise histórica". In: Educação \& Realidade. Porto Alegre, v. 20, n. 2, jul./dez. 1995, p. 71-99. 
THERBORN, Göran. Sexo e Poder: a família no mundo 1900-2000. Tradução de Elisabete Bilac. São Paulo: Contexto, 2006. 